\author{
Erratum
}

\title{
Loss in acoustic metasurfaces: a blessing in disguise - ERRATUM
}

\section{Nikhil JRK Gerard and Yun Jing}

doi: https://doi.org/10.1557/mrc.2019.148, Published by Materials Research Society with Cambridge University Press, 14 November 2019

(a)
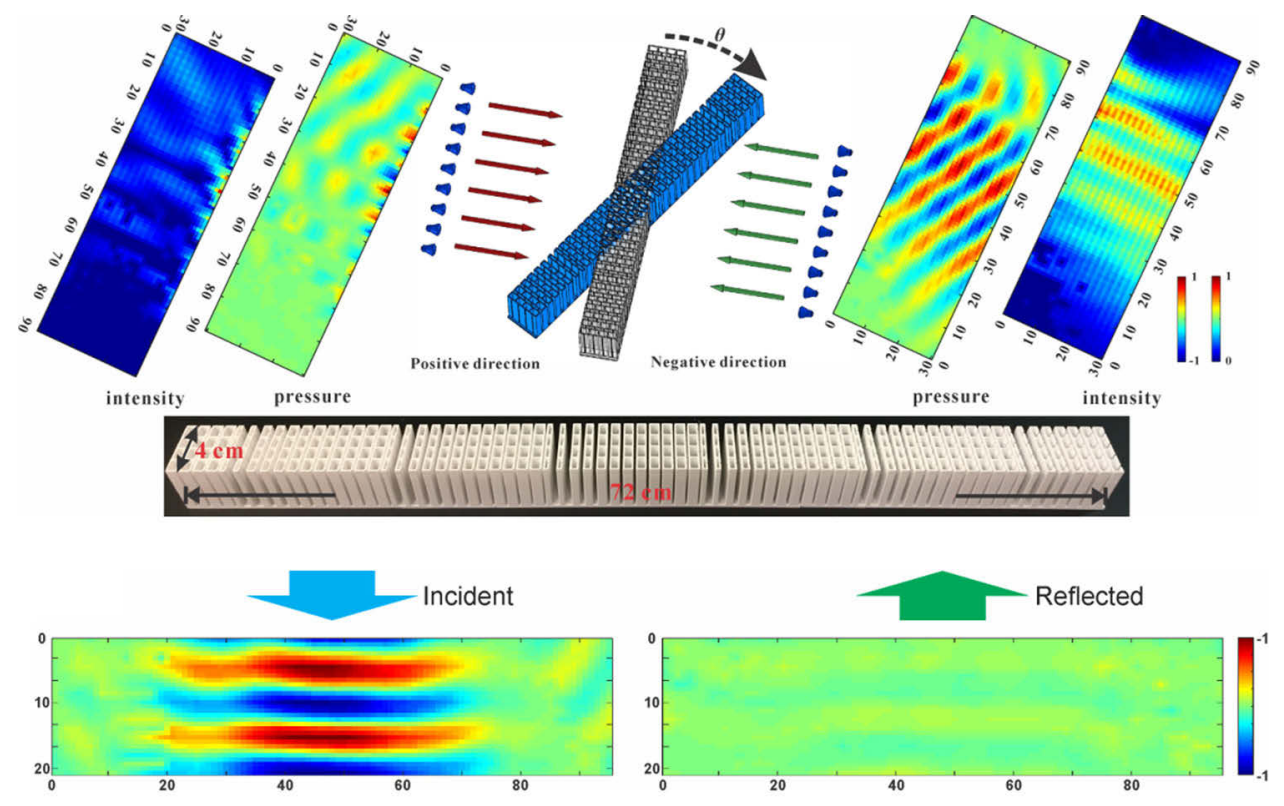

(b)

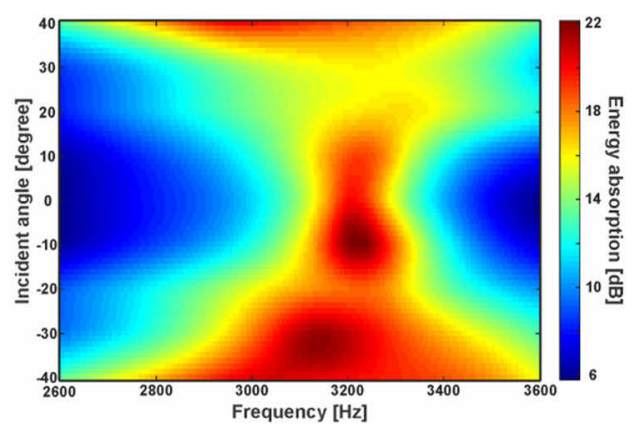

In the original publication of Gerard and Jing, ${ }^{1}$ the $\mathrm{a}$ and $\mathrm{b}$ designations of Figure 2 were placed in a manner that could have been misinterpreted. A corrected version of Figure 2 is above to avoid ambiguity.

The publisher apologizes for this error.

\section{Reference}

1. NJRK Gerard and Y Jing: Loss in acoustic metasurfaces: a blessing in disguise. MRS Comm. doi: 10.1557/mrc.2019.148 (2019). 